
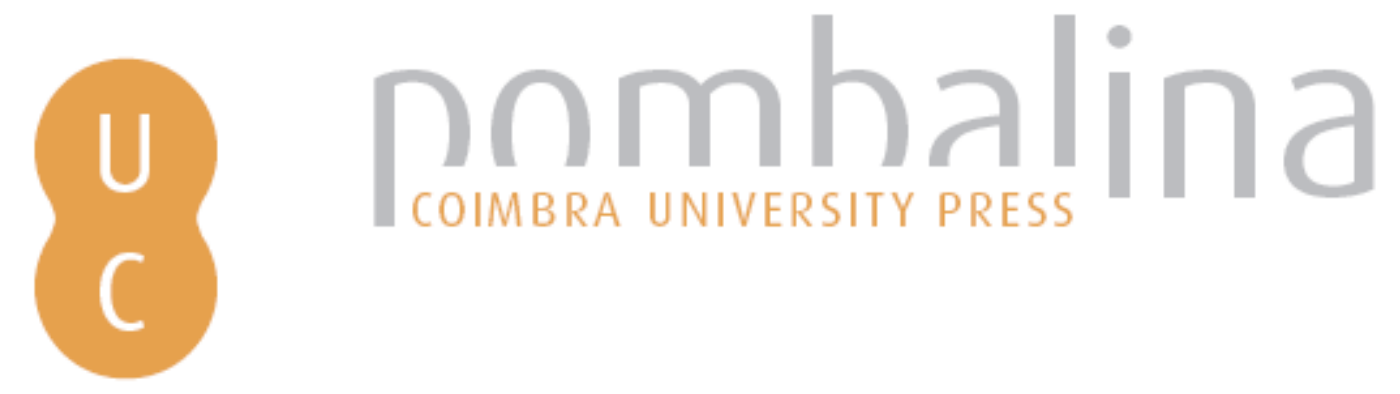

\title{
Grupos de pesquisa em Ciência da Informação no Brasil
}

Autor(es): Oliveira, Marlene de

Publicado por: Imprensa da Universidade de Coimbra

URL

persistente: URI:http://hdl.handle.net/10316.2/31888

DOI: $\quad$ DOI:http://dx.doi.org/10.14195/978-989-26-0869-3_9

Accessed : $\quad$ 26-Apr-2023 05:42:34

A navegação consulta e descarregamento dos títulos inseridos nas Bibliotecas Digitais UC Digitalis, UC Pombalina e UC Impactum, pressupõem a aceitação plena e sem reservas dos Termos e Condições de Uso destas Bibliotecas Digitais, disponíveis em https://digitalis.uc.pt/pt-pt/termos.

Conforme exposto nos referidos Termos e Condições de Uso, o descarregamento de títulos de acesso restrito requer uma licença válida de autorização devendo o utilizador aceder ao(s) documento(s) a partir de um endereço de IP da instituição detentora da supramencionada licença.

Ao utilizador é apenas permitido o descarregamento para uso pessoal, pelo que o emprego do(s) título(s) descarregado(s) para outro fim, designadamente comercial, carece de autorização do respetivo autor ou editor da obra.

Na medida em que todas as obras da UC Digitalis se encontram protegidas pelo Código do Direito de Autor e Direitos Conexos e demais legislação aplicável, toda a cópia, parcial ou total, deste documento, nos casos em que é legalmente admitida, deverá conter ou fazer-se acompanhar por este aviso.

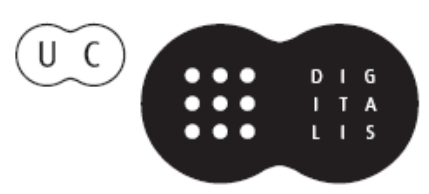


Maria Manuel Borges

Elias Sanz Casado

Coordenação

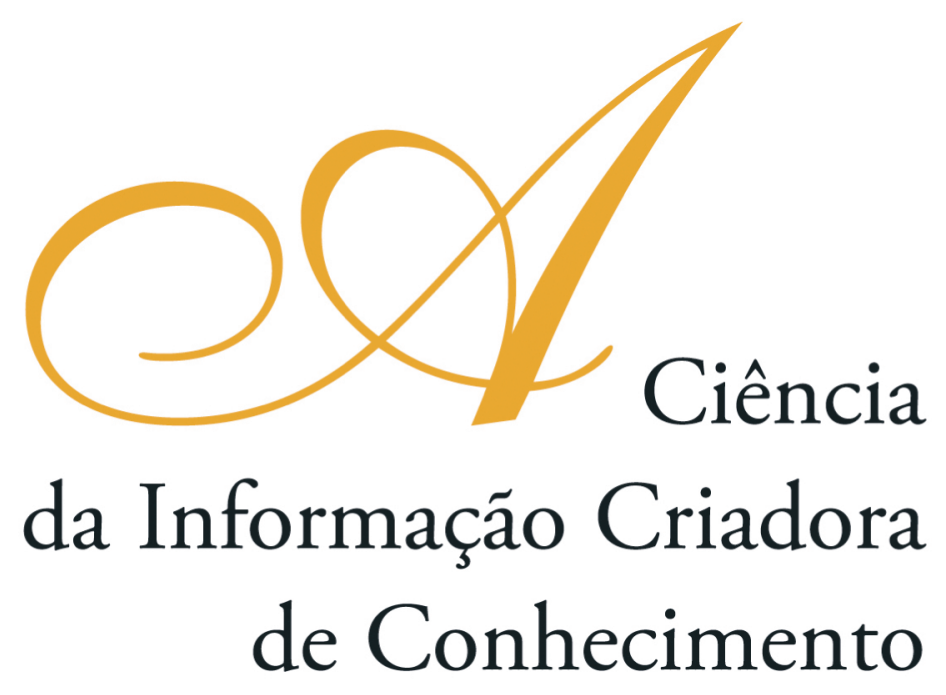

Vol. I I

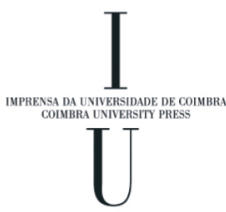

- COImbra 2009 


\title{
Grupos de Pesquisa em Ciência da Informação no Brasil
}

\author{
Marlene de Oliveira \\ Universidade Federal de Minas Gerais (Brasil)
}

\section{Resumo}

Resultados de pesquisa financiada pelo Conselho Nacional de Desenvolvimento Científico e Tecnológico para estudar os grupos de pesquisa em Ciência da Informação (CI), cadastrados no Diretório dos Grupos de Pesquisa dessa agência. Os procedimentos metodológicos envolveram coleta de dados junto às bases do Diretório de Grupos de pesquisa e à base de currículos da plataforma lattes do CNPq. Recorreu-se, também, às bases do sistema de acompanhamento da pós-graduação da Coordenação de Aperfeiçoamento de Pessoal de Nível Superior (CAPES). Selecionaram-se três grandes categorias de análise: grupos de pesquisa; perfil do pesquisador; produção científica. Identificaram-se 103 grupos de pesquisa na base de dados referentes ao ano 2004, analisados e distribuídos por regiáo geográfica, perfil do pesquisador, temáticas estudadas e canais de comunicação utilizados. Os grupos de pesquisa na área não estão bem distribuídos. Há concentração no Sudeste e Sul do País. Os componentes dos grupos são integrados por doutores, mestres e bolsistas de iniciação científica. Os perfis dos pesquisadores concentram-se em bibliotecários com pós-graduação em CI. Há participação de graduados em outras áreas mas com pós-graduação em CI. Os temas mais pesquisados foram tecnologia da informaçáo, organizaçấo do conhecimento, questôes sociais e indústria da informaçấo.

\begin{abstract}
This paper presents the results of a study about the Information Science groups registered in the Directory of research groups of CNPq, a Brazilian governmental agency. Data collection utilized the directory database, CNPq's Lattes database of curricula vitae as well as the Capes database of graduate programs evaluation system. The research used three categories of analysis: research groups, researcher profile, and scientific publications. In the year 2004, 103 research groups were identified. These were analyzed by geographic region, researcher profile, research topics and channels of communication utilized. The results demonstrated that research groups are not evenly distributed. They are concentrated in the south and southeast regions. Research groups are composed by members with doctoral and masters degrees as well as undergraduate research assistants. Most researchers hold undergraduate degrees in librarianship and graduate studies in Information Science although some have undergraduate degrees in other areas and graduate in Information Science. The topics mostly addressed were information technology, knowledge organization, social issues and the information industry.
\end{abstract}

\section{Introdução}

Um dos desafios que hoje se apresentam para a Ciência da Informação - CI é o de desenvolver a capacidade de refletir e teorizar sobre suas práticas para, assim, construir conhecimentos teóricos. Como em outras áreas do conhecimento, o caminho 
da investigação científica tem sido o mais comumente trilhado para a construçáo de conhecimentos e a produção científica na área conduz, por sua vez, os avanços e revela as tendências epistemológicas da área. A pesquisa e a produção científicas são temas presentes na literatura atual, tanto no Brasil como no exterior, o que parece ser indício de maturidade da área, ao demonstrar preocupação em se fortalecer teoricamente.

A produção científica da área, no Brasil, iniciou-se na década de 80 , com poucos estudos, tornando-se questấo de pesquisa científica, com mais freqüência, a partir de 1990. Observa-se que a preocupação com a investigação científica da CI vem crescendo desde a década de 90, fato este que pode constituir um indicador de maturidade da área. A presente pesquisa faz parte da linha de estudos do Grupo Fundamentos Epistemológicos da Ciência da Informação, certificado pela Universidade Federal de Minas Gerais (UFMG), no Diretório de Grupos de Pesquisa do Conselho Nacional de Desenvolvimento Científico e Tecnológico (CNPq).

É uma pesquisa descritiva, com o objetivo de identificar e caracterizar pesquisadores e grupos de pesquisa da área, cadastrados no Diretório de Grupos de Pesquisa do CNPq. Para isso, analisou-se o perfil dos pesquisadores quanto à formação acadêmica, área e instituição. A produção científica efetuada foi analisada por tipo, área temática, espaços de intercâmbio com outros pesquisadores de outras instituiçóes e com grupos somente da graduação.

O Diretório dos Grupos de Pesquisa do CNPq registra o grupo de pesquisa e suas atividades por meio dos seguintes itens: identificação; recursos humanos; linhas de pesquisa; indicadores de recursos humanos $(\mathrm{RH})$; indicadores de produção. Assim, reúne informaçóes sobre a data de criação do grupo, número de pesquisadores, estudantes, técnicos e linhas de pesquisa em andamento, setores de atividades envolvidos, produção científica, tecnológica e artística geradas pelos grupos e, mais recentemente, os padróes de interaçáo dos grupos com o setor produtivo.

A base empírica do estudo integrou informaçôes disponibilizadas no Diretório de Grupos de Pesquisa na base de 2004, com a ressalva de que o Diretório é atualizado de dois em dois anos, mas a base completa torna-se disponível para consulta e pesquisa somente ao término do biênio. Logo, a base de 2006 só estaria completa para pesquisa no final desta pesquisa, enquanto, na etapa da coleta dos dados, a base de dados referente ao ano 2004 apresentava-se completa. A busca na base para reconhecimento dos grupos foi feita pela expressão Ciência da Informação. Os dados da produção científica dos pesquisadores foram extraídos da base de currículos da Plataforma Lattes do CNPq. Foi uma tarefa que exigiu cuidados porque foi filtrada a produção do pesquisador depois de sua inclusão no grupo de pesquisa, a produtividade anterior ao seu ingresso no grupo foi descartada. Caso contrário, a produção geral causaria distorçóes quanto à temática selecionada. A análise da produção científica concentrou-se nos artigos de revistas científicas. È importante destacar que o produto disseminado em revistas científicas, notadamente aquelas incluídas na base de dados Qualis da Coordenação de Aperfeiçoamento de Pessoal de Nível Superior (CAPES) são de fácil acesso, enquanto os livros, grande parte na forma de coletâneas, são de difícil acesso.

Assim como em outros campos do conhecimento, a investigação científica na CI é mais densa nos cursos de pós-graduação. A área conta com sete programas de mestrado e três de doutorado. Os grupos de pesquisa cadastrados em CI, na base de 
dados de 2004, integram muitos e variados grupos dedicados a estudos de informação dispersos em cursos de graduação e pós-graduação, assim como em instituiçóes de ensino superior (IES) em diferentes regiôes do País.

Atualmente, o CNPq não oferece em seu site, uma definição de grupo de pesquisa, mas para uso, neste estudo, adotaram-se algumas características semelhantes e complementares que definem o grupo de pesquisa. A Universidade Estadual de São Paulo (UNESP) definiu, em 2007, o grupo de pesquisa como um conjunto de indivíduos organizados hierarquicamente em torno de uma ou, eventualmente, duas lideranças. O fundamento dessa estrutura hierárquica reside na experiência, no destaque e na liderança no terreno científico ou tecnológico. Nesse conjunto, existe envolvimento profissional e permanente com a atividade de pesquisa. As atividades se organizam em torno de linhas e temas de pesquisas, e, em algum grau, tal conjunto compartilha instalaçóes e equipamentos.

O grupo deve ser constituído por, pelo menos, dois membros (docente, pesquisador, pós-doutorando) e, no mínimo, por dois alunos (iniciação científica, mestrando, doutorando). Todos os membros do grupo, inclusive os alunos, devem possuir curriculum Lattes e proceder às atualizaçôes conforme normas do CNPq. (UNESP, 2007).

Após a identificação dos grupos, líderes de grupos e nomes dos pesquisadores, foi utilizada a base de dados de Currículos da Plataforma Lattes para levantamento da produção científica de cada participante do grupo. Em seguida foi analisado o texto completo dos artigos disponíveis em revistas on-line.

A base empírica do estudo, conforme já explicado, concentrou-se nas bases de dados do Diretório de Grupos de Pesquisa, referentes aos dados do censo de 2004, e ao banco de currículos da Plataforma Lattes, também do CNPq. Os componentes e temáticas dos grupos foram informaçóes coletadas no Diretório. Quanto aos dados das publicaçóes sobre a produção dos pesquisadores foram, reunidos por meio do Diretório e dos currículos dos membros de cada grupo, cadastrados na plataforma Lattes do CNPq.

A análise dos dados incluiu: (1) grupos de pesquisa - identificação dos grupos; instituiçôes que os abrigam; distribuição dos mesmos por região e instituiçôes; (2) perfil dos pesquisadores - formação e titulação acadêmica; vínculo empregatício; (3) produção científica - tipo de registro - temas pesquisados.

\section{Referencial teórico}

A investigação científica na CI tem sido objeto de estudos recentes publicados em revistas nacionais e estrangeiras. Tais estudos, contudo, só apareceram, com mais nitidez, na literatura da área, a partir do final dos anos 80 . Na literatura estrangeira, há registros de que a partir da década de 60 houve avanços na pesquisa em Ciência da Informação e Biblioteconomia (CIB), mas não o suficiente para entender a pesquisa científica como um caminho que possa conduzir ao progresso da área.

Pinheiro (1997) desenvolveu importante pesquisa como tese de doutoramento sobre a CI no exterior. A preocupação do estudo foi o de apreender a "gênese da Ciência da Informação, seu corpo de conhecimentos, definiçóes e conceitos, suas leis e teorias, enfim, o conjunto de elementos que a caracterizam como campo do conhecimento 
[...]" A base empírica do estudo dessa autora foram os artigos de revisão publicados no Annual Review Information Science and Tecnology (ARIST), entre 1966 e 1995, dados coletados em 30 volumes, com 307 artigos. Os resultados foram relevantes tanto para identificar os construtos teóricos da CI como para iluminar a questáo da interdisciplinaridade.

Um estudo desenvolvido por Bufrem (1996) diz respeito às opçóes metodológicas explicitadas nas dissertaçôes, também do Programa de Pós-Graduação do Instituto Brasileiro de Informação em Ciência e Tecnologia (IBICT) / Universidade Federal do Rio de Janeiro (UFRJ). O resultado da análise das dissertaçóes desenvolvidas no Programa indicou a presença marcante da pesquisa empírica e o predomínio das abordagens quantitativas, notadamente no primeiro período estudado, de 1972 a 1984. Ainda segundo a autora, a partir da década de 80 , os trabalhos passaram a sugerir maior reflexáo sobre a prática e até mesmo críticas aos excessos dos resultados quantitativos.

Cabe ressaltar que o programa da USP não tinha a denominação de Ciência da Informaçáo até 1993. Em 1972, foi criada uma área de concentração em Biblioteconomia no Programa de Pós-Graduaçáo de Ciências da Comunicação, e, em 1991, a área de concentração consolida-se como Ciência da Informação e Documentação.

Os resultados da pesquisa mostraram alguns dados interessantes. Em sua conclusáo, atenta para o fato de que as pesquisas desenvolvidas caracterizam-se por incipiente delimitação de seu objeto de estudo; pouca explicitação dos conceitos e metodologias utilizadas pela diversidade de teorias importadas de outras áreas e reduzida discussão sobre essa importaçáo. Acrescenta-se a isso o emprego de métodos quantitativos em detrimento de métodos qualitativos.

Por sua vez, o estudo de Oliveira (1998) teve como intuito analisar as pesquisas financiadas pelo CNPq, de 1984 a 1993, para apreender as características e as peculiaridades da investigação científica em CI. Foram estudados 94 relatórios de pesquisas desenvolvidos por 36 doutores e 42 mestres. Os resultados apontaram crescente melhoria na formação de pesquisadores. Na década de 80 , eram poucos os doutores, havendo incremento considerável nos anos seguintes. A fragmentaçáo da pesquisa em diversos temas foi uma característica predominante no período estudado. Não se identificou a manutençâo de estudos em temas básicos ou prioritários ao longo do tempo estudado. O fato aponta falta de objetividade da área na busca de resultados de pesquisa causando, com isso, pulverização de recursos.

Dinah Población (2003) desenvolveu estudos sobre a produtividade científica na esfera das linhas de pesquisa dos cursos de Pós-Graduação em Ciência da Informação no período de 2000 a 2002. Como base empírica do estudo, analisou dissertaçôes e teses dos programas de pós-graduaçáo da área, no período de 1990 a 2002. Os dados apontaram, também, o número de profissionais titulados que formam a comunidade de pesquisadores e mostram as categorias temáticas que agregam as dissertaçôes e teses. Aqui cabe um parêntese para esclarecer que Población desenvolve estudos sobre a literatura brasileira da CI desde 1993. A ampliação dessas pesquisas, com a colaboraçáo de outros pesquisadores da ECA / USP e, também, de outras instituiçôes, conduziu à criação do Núcleo de Pesquisa de Produção Científica. A partir dos estudos do Núcleo foram criados produtos, como: bases de dados sobre os eventos da Ciência da Informação, Biblioteconomia e Arquivologia; base de dissertaçôes e teses da CI; informaçóes sobre os programas de pós-graduação, suas linhas de atuação e corpo docente. 
Mais recentemente, Gomes (2006) desenvolveu trabalho visando analisar as dissertaçóes produzidas no Programa de Pós-Graduação em Ciência da Informação (PPGCI) da UFMG. Identificou as temáticas e as abordagens metodológicas predominantes. As pesquisas concentraram-se nos temas: gerência de serviços e unidades de informação; estudo de usuários; demanda e uso de informação; divulgação e produção editorial.

O estudo dessa literatura aponta compromisso da área em se conhecer e mostrar avanços. Os estudos desenvolvidos não utilizam os mesmos instrumentos de pesquisa, como a mesma relação de temas estudados, uma vez que foram elaborados em períodos de tempo deferentes. Nas últimas décadas, a área sofreu fortes influências, notadamente tecnológicas, modificou e progrediu muito. Isso aumenta a dificuldade de integraçáo dos conhecimentos gerados nos estudos, conforme verificado por Gomes (2003).

\section{Obstáculos e limitaçôes da pesquisa}

O caminho desta pesquisa foi complexo. Em primeiro lugar, dentro do conjunto de grupos encontrou-se certo número deles fora do escopo da Ciência da Informação. Conforme informaçóes prestadas por uma técnica do CNPq que acompanha a alimentação da base de dados do Diretório de Grupos de Pesquisa, o CNPq não filtra as informaçôes que recebe. Nesse sentido, pelo menos no início de suas atividades, muitos grupos foram registrados incorretamente, ou seja, não pertencem à área de CI ou apenas detinham com ela correlação tênue. Dentre tais grupos, destacamos o Grupo Bioética e Ciência da Informação (ANIS) e um grupo da Universidade Federal da Bahia (UFBA), denominado Estudos e Pesquisa em Geoquimica e Meio Ambiente Aplicadas a Processos Exógenos. Contudo, não retiramos tais grupos do estudo, uma vez que a pesquisa se propôs a estudar os Grupos de Pesquisa cadastrados e recuperados em Ciência da Informação.

Atualmente, percebe-se que muitas universidades federais referendam os grupos proponentes antes do cadastro na referida base, o que deverá trazer mais confiabilidade aos dados disponibilizados.

A produção de cada membro do grupo só foi coletada a partir da data de sua entrada no grupo. Considerando que muitos pesquisadores mudaram de grupos, instituiçóes , etc., este foi um fato que exigiu cuidados em pequenos detalhes.

O acesso ao banco de currículos da Plataforma Lattes também apresentou dificuldades. Alguns pesquisadores não mantinham currículos atualizados, o que pode ter gerado certas distorçôes na produção científica de algumas instituiçôes. Os dados fornecidos pelos pesquisadores, muitas vezes, mostram-se falhos e incorretos, o que exigiu consulta em outras bases de dados, como o portal da Scientific Electronic Library Online (www.scielo.br) para identificação de autores e artigos.

Outros problemas detectados foram:

- Alguns pesquisadores lideravam mais de um grupo de pesquisa, na mesma instituição, em temáticas diferentes.

- Parece haver pouco entendimento quanto à função de um grupo de pesquisa dentro da instituiçãáo, ou unidade, e no âmbito da própria área. 
- A produtividade dos grupos de pesquisa mostrou-se muito pequena em relação ao período estudado, o que não proporcionou riqueza para reflexóes e consideraçóes em certos aspectos da pesquisa.

\section{Análise dos resultados}

Os resultados obtidos no início da pesquisa pareciam animadores: detectaram-se 103 grupos, um percentual razoável de grupos numa área de pesquisa ainda recente, como é a CI. Contudo, na medida em que as atividades da pesquisa se desenvolviam, os dados iniciais foram gradativamente aprofundados em sua análise e mais bem compreendidos no contexto geral da pesquisa. De início, os 103 grupos foram divididos por regiāo (Tabela 1 ).

Conforme observado em estudos anteriores, não só em CI mas em outras áreas do conhecimento, a maior produtividade científica concentra-se em instituiçóes do Sudeste. É importante observar que as regióes que detêm o maior número de grupos são aquelas que abrigam maior número de instituiçóes de pesquisas e de programas de pós-graduação. $\mathrm{O}$ maior número de programas de pós-graduação está nessa região, com quatro programas e um curso de mestrado, quando da coleta dos dados. A regiáo Sul, por seu turno, abriga dois cursos de mestrado e o Nordeste, um programa e um curso de mestrado. A regiáo Centro-Oeste detém um total de 12 grupos, contudo o maior número deles concentra-se em Brasília, Distrito Federal (DF), com 11 grupos. Para evitar distorçôes foi feita um divisão entre Distrito Federal e o Centro-Oeste, como um todo.

Tabela 1 - Distribuição dos grupos de pesquisa por regiāo

\begin{tabular}{|l|l|l|}
\hline Brasil / Regióes & $\mathrm{N}$ & $\%$ \\
\hline Sudeste & 50 & 48,5 \\
\hline Sul & 20 & 19,4 \\
\hline Nordeste & 18 & 17,5 \\
\hline Distrito Federal & 11 & 10,7 \\
\hline Norte & 3 & 2,9 \\
\hline Centro-Oeste & 1 & 1,0 \\
\hline TOTAL & 103 & 100,00 \\
\hline
\end{tabular}

As datas de criação correlacionadas ao número de grupos trazem informações animadoras. O primeiro grupo de pesquisa foi criado em 1978 e desde entâo o número de grupos vem crescendo, ano a ano, o que parece ser um indicador não só de crescimento, mas, também, de amadurecimento da CI. O crescimento numérico dos grupos pode indicar melhor formação dos RH para pesquisa e, conseqüentemente, incremento de pesquisas e de novos conhecimentos, na área.

Assim como a distribuição dos recursos humanos qualificados para a pesquisa e a produção de conhecimentos, a maioria dos grupos de pesquisa também se concentra no Sudeste $(48,5 \%)$. Isso em função de a região abrigar a maior quantidade de universidades e de centros de pesquisas. A região Sul está em segundo lugar, com 
$19,4 \%$ dos 103 grupos de pesquisa e a região Nordeste em terceiro, com 17,5\%. O número de grupos localizados no DF foi destacada, uma vez que se responsabiliza por $10,7 \%$ do total de $11,7 \%$ do Centro-Oeste (Tabela 2).

Tabela 2 - Distribuição dos grupos por instituição

\begin{tabular}{|c|c|c|c|c|c|c|c|c|c|c|c|c|}
\hline \multicolumn{2}{|l|}{ Norte } & \multicolumn{2}{|c|}{ Nordeste } & \multicolumn{2}{|l|}{ Sudeste } & \multicolumn{2}{|l|}{ Sul } & \multicolumn{2}{|l|}{$\begin{array}{l}\text { Centro- } \\
\text { Oeste }\end{array}$} & \multicolumn{2}{|c|}{$\begin{array}{l}\text { Distrito } \\
\text { Federal } \\
\end{array}$} & \\
\hline UFAM & 1 & UFBA & 7 & FGV/EAESP & 1 & CERTI & 1 & UFMT & 1 & ANIS & 1 & \\
\hline \multirow{17}{*}{ UPBA } & 2 & UFC & 2 & FIOCRUZ & 1 & FEE & 1 & & & UNB & 10 & \\
\hline & & UFMA & 1 & INT & 1 & TECPAR & 1 & & & & & \\
\hline & & UFPB & 3 & POLIS & 1 & UDESC & 2 & & & & & \\
\hline & & UFPE & 2 & PUC Minas & 1 & UEL & 7 & & & & & \\
\hline & & UFPI & 1 & PUC-RJ & 1 & UEM & 1 & & & & & \\
\hline & & UFRN & 1 & UFP & 1 & UFPR & 2 & & & & & \\
\hline & & UNEB & 1 & UMESP & 1 & UFSC & 3 & & & & & \\
\hline & & & & PUC-CAMP & 1 & UFSM & 2 & & & & & \\
\hline & & & & UFES & 2 & & & & & & & \\
\hline & & & & UFF & 2 & & & & & & & \\
\hline & & & & UNIRIO & 3 & & & & & & & \\
\hline & & & & FBN & 4 & & & & & & & \\
\hline & & & & UFSCAR & 5 & & & & & & & \\
\hline & & & & UNESP & 5 & & & & & & & \\
\hline & & & & USP & 6 & & & & & & & \\
\hline & & & & IBICT & 7 & & & & & & & \\
\hline & & & & UFMG & 7 & & & & & & & TOTAL \\
\hline Subtotal & 3 & & 18 & & 50 & & 20 & & 1 & & 11 & 103 \\
\hline
\end{tabular}

O formulário de registro na base Diretório dos Grupos de Pesquisa oferece opção para descrição do grupo sob o título Repercussóes do trabalho do grupo, o que conduz às idéias de influência exercida e prestígio alcançado. Tal categoria não guarda a objetividade necessária para que o grupo se defina e descreva seus propósitos. Talvez por esta razão, os grupos descrevem, no item repercussóes do trabalho em grupo, diferentes textos. Alguns grupos se autodefinem. Outros descrevem sua gênese e desenvolvimento. Outros discorrem sobre seus recursos humanos e há os que descrevem as repercussóes pretendidas:

O grupo de pesquisa [...] tem como objetivo estudar e pesquisar os ambientes empresariais $[\ldots]$

O grupo tem como referencial de origem o ano de 1999 a partir de trabalhos e ações $[\ldots]$

[...] os resultados das pesquisas nas linhas privilegiadas pelo grupo podem servir para o planejamento de sistema de informaçáo,especialmente no que diz respeito às atividades de tratamento da informação, análise de assunto, indexação [...] 
Dessa maneira, o formulário de cadastramento do grupo não oferece espaços determinados para objetivos, gênese e metas, o que náo possibilitou a reuniáo de idéias sobre o entendimento da comunidade a respeito de grupo de pesquisa.

Por outro lado, as instituições e o número de grupos abrigados nos programas de pós-graduaçáo estáo descritos na Tabela 3.

Tabela 3 - Grupos de pesquisas por instituiçâo de pós-graduação

\begin{tabular}{|c|c|}
\hline INSTITUIÇÓES & GRUPOS DE PESQUISA \\
\hline UNB & 10 \\
\hline IBICT & 7 \\
\hline UFBA & 7 \\
\hline UFMG & 7 \\
\hline USP & 6 \\
\hline UNESP & 5 \\
\hline UFPB & 3 \\
\hline UFSC & 3 \\
\hline UFF & 2 \\
\hline PUC-CAMP & 1 \\
\hline TOTAL & 51 \\
\hline
\end{tabular}

É preciso salientar que os programas de pós-graduação ainda reúnem grande parte do total, ou seja, 51 grupos de pesquisa e apresentam a produção mais densa dentre os grupos. Contudo, a maior parte dos 52 grupos se dispersa em cursos de graduaçáo em Biblioteconomia e em outras áreas, a exemplo de Comunicaçáo e Administração, além de IES que se interessam por estudos de informação, internet, etc. Essa constatação pode ser um bom indicador de que as questóes de informação despertam interesses também em outros campos de conhecimento.

\section{Perfil do pesquisador}

As informações sobre os pesquisadores foram coletadas na base de currículos Lattes do $\mathrm{CNPq}$, como antes enunciado. Os participantes dos grupos foram classificados por regiáo e formação acadêmica, conforme descrito na Tabela 4 . 
Tabela 4 - Distribuição dos pesquisadores dos grupos de pesquisa por formação acadêmica

\begin{tabular}{|c|r|r|r|r|r|r|r|r|}
\hline Regiáo & Grupos & $\begin{array}{c}\text { Năo } \\
\text { acadêmico }\end{array}$ & $\begin{array}{c}\text { Gradua- } \\
\text { çáo }\end{array}$ & $\begin{array}{c}\text { Especia- } \\
\text { lizaçáo }\end{array}$ & $\begin{array}{c}\text { Mestra- } \\
\text { do }\end{array}$ & $\begin{array}{c}\text { Douto- } \\
\text { rado }\end{array}$ & $\begin{array}{c}\text { Pós- } \\
\text { Doutorado }\end{array}$ & TOTAL \\
\hline Sudeste & 50 & 0 & 5 & 9 & 42 & 167 & 35 & 258 \\
\hline Centro-Oeste & 12 & 1 & 22 & 10 & 28 & 72 & 16 & 149 \\
\hline Sul & 20 & 0 & 8 & 8 & 45 & 64 & 4 & 129 \\
\hline Nordeste & 18 & 0 & 2 & 6 & 33 & 67 & 18 & 126 \\
\hline Norte & 3 & 0 & 1 & 2 & 7 & 3 & 0 & 13 \\
\hline TOTAL & 103 & 1 & 38 & 35 & 155 & 373 & 73 & $\mathbf{6 7 5}$ \\
\hline
\end{tabular}

O total de RH envolvidos nos grupos de pesquisa em CI, na base estudada, soma 675 participantes, dentre os quais 375 pesquisadores com titulação de doutor, 155 mestres, 35 com especialização em diferentes cursos, 38 apenas graduados e uma pessoa ainda não graduada. Esses recursos humanos de pesquisa em Ciência da informação estão distribuídos nos diversos grupos. Poucos mestres lideraram grupos, no período estudado, e somente um grupo apresentava um líder de pesquisa com apenas graduaçáo. Nota-se que a grande maioria e todos os que se vinculavam a um programa de pósgraduaçáo apresentavam como líder um pesquisador-doutor.

\section{Temas pesquisados}

A classificação dos grupos de pesquisa por temas e subtemas da CI é uma tarefa difícil e complexa. Uma das dificuldades está relacionada à própria natureza da área, a qual náo apresenta o mesmo comportamento em pesquisa como o de outras áreas consolidadas. Suas teorias e metodologias, ainda em fase de construção, apresentam-se fragmentadas, além de não contarem com consenso entre os pesquisadores sobre sua própria delimitação,(OLIVEIRA, 1998). Em segundo lugar, a formação de grande parte dos lideres e pesquisadores origina-se de áreas ora mais próximas ora mais distantes à $\mathrm{CI}$ ou, muitas vezes, o grupo se dedica a uma nova área de interface, ou seja, novos contextos de informação. A produção de tais pesquisadores encontra-se numa regiáo nebulosa, limítrofe entre a área de formação inicial do pesquisador e a da CI, sua formação em nível de doutorado. As temáticas dos grupos foram reunidas nas 11 classes gerais da taxonomia adotada, conforme listagem da Tabela 5 .

Conforme os temas que nomeiam os grupos de pesquisa, a temática que reúne o maior número de grupos é a de tecnologias da informação. Isso é comprovado pela existência de muitas pesquisas e artigos publicados, uma vez que 20 grupos estudam variados subtemas da temática. É uma classe que abriga pesquisas na internet, navegadores, portais, diretórios, intranets, softwares e hardwares. Inclui, também, estudos sobre gestão de documentos, inteligência artificial, telecomunicaçôes, segurança, controle de acesso e criptografia. Isto parece uma preocupaçáo pertinente, uma vez que a reserva de mercado para produção de tecnologias, instituída na década de 70 , causou um gap na produção e no uso de tecnologias em todos os setores da sociedade, mas, principalmente, na automação das bibliotecas e de outros serviços de informação no País. 
Tabela 5 - Classificação temática dos grupos de pesquisa consolidados, base de dados 2004

\begin{tabular}{|l|l|l|}
\hline CLASSIFICAÇÃO TEMÁTICA DOS GRUPOS DE PESQUISAS & $\mathrm{N}$ & $\%$ \\
\hline 01 - Tecnologia da informaçáo & 20 & 19 \\
\hline 02 - Organizaçáo do conhecimento & 16 & 15 \\
\hline 03 - Questóes Sociais & 16 & 15 \\
\hline 04 - Indústria da Informação & 13 & 13 \\
\hline 05 - Pesquisa em Ciência da Informaçáo & 11 & 11 \\
\hline 06 - Bibliotecas e serviços bibliotecários & 6 & 6 \\
\hline 07 - Fontes e aplicaçóes para assuntos específicos & 6 & 6 \\
\hline 08 - Produçáo editorial & 5 & 5 \\
\hline $09-$ Profissáo da informaçáo & 5 & 5 \\
\hline $10-$ Informaçáo e questōes governamentais e legais & 4 & 4 \\
\hline $11-$ Sistemas e serviços de informaçáo eletrônica & 1 & 1 \\
\hline TOTAL & 103 & 100 \\
\hline
\end{tabular}

O segundo tema com maior número de grupos diz respeito às temáticas de organização do conhecimento, o qual agrega temas, como tesauros, listas de autoridade, catalogação e classificação, elaboração de resumos, indexação, revisão e padróes e protocolos. Empatados no segundo lugar, também com 16 grupos, estão as questôes sociais, temática que inclui tópicos, tais como: ética da informação, plágio, credibilidade: alfabetização informacional, educação continuada e sociedade da informação. Grande parte das questóes de pesquisa nessa temática vinculam-se a estudos de comunidades e seu acesso à informação, telecentros, além de informação e cidadania.

A temática indústria da informação agrega os novos contextos de informação como informação e gestão do conhecimento, mercados e atores, economia e preços e, por fim, marketing e comércio eletrônico. A produção dos grupos, neste caso, concentrouse em grande parte nos estudos sobre informação e gestão do conhecimento.

Foi animador constatar que a temática pesquisa em Ciência da Informação ocupa um lugar destacado no ranking das questóes da área. Entender suas teorias, seus conceitos básicos, suas metodologias, suas definiçôes e suas aplicaçóes consiste em movimento que vem crescendo entre os pesquisadores, mas já é visível na pesquisa.

Verificaram-se, contudo, poucas pesquisas sobre bibliotecas e serviços bibliotecários (Tabela 5), o que causa alguma apreensão. Os problemas das bibliotecas brasileiras estão sendo estudados? Ou as bibliotecas não apresentam problemas de pesquisa? Ou os programas de pós-graduação não orientam tais questóes? A este respeito, Oliveira (1998) chama a atenção para o fato de que os temas de pesquisa em CI fragmentam-se cada vez mais, o que pode ser observado na produção de textos em assuntos localizados na periferia da área. Tal constatação vai de encontro às idéias de White e McCain (apud SARACEVIC, 1999, p. 1.055), que usa a metáfora: "[...] tal como as coisas se tornaram, a Ciência da Informação parece algo como a Austrália: altamente desenvolvido em suas áreas costeiras e com um interior escassamente povoado." A produçáo de textos localiza-se na periferia da área com temas importantes e relevantes. Por outro lado, questôes como organização e recuperação da informação, além de outras complexas como aquelas ligadas à internet são negligenciadas. Essas 
questōes ainda necessitam de estudos, reflexôes e grupos de pesquisa empenhados em seu conhecimento.

É preciso informar que a indicação do doutorado em comunicação e documentação refere-se ao Programa de Doutorado em Comunicação da USP, que instalou área de concentração em Ciência da Informação e Documentação, em 1991, como antes enunciado. Em 1993, foi aprovado no Conselho de Pós-Graduaçáo da USP e, em 2006, foi reconhecido pela CAPES e ganhou autonomia em relação ao curso de ciências da comunicação. Castro (2009) explica, também, que os cursos de mestrado em Biblioteconomia transformaram-se em programas de mestrado e doutorado em Ciência da Informação, ainda na década de 90.

Ao analisar os temas mais estudados pelos pesquisadores constantes dos grupos, verificou-se que as temáticas mais investigadas por eles individualmente não são as mesmas dos assuntos dos grupos. Um pesquisador, por exemplo, vinculado a um grupo de representação da informação publica artigos sobre produção cientifica, gestão da informação e outros tópicos. Conforme a literatura estudada, o pesquisador que se dedica a uma só temática possui maiores condiçôes de resolver problemas de pesquisa do assunto escolhido. Ao se dedicar a vários temas, sobretudo em atividade de orientaçáo, há dispêndio de tempo e de leituras do pesquisador, com retorno não compatível, o que conduz, também, à fragmentação temática da área.

Observou-se que alguns pesquisadores da CI, oriundos de outras áreas do conhecimento, publicam alguns artigos na área e continuam, em sua maior parte, a investigar problemas da sua área de origem. Exemplificando: pesquisadores de comunicação social, psicologia e outros com pós-graduação em Ciência da Informação, que integram grupos de pesquisa, tendem a publicar mais em suas áreas de origem.

Os artigos disseminados em periódicos foram selecionados por título, para que se verifique quais as que mais publicam artigos em CI, como disposto na Tabela 6. A relação das revistas mais utilizadas pelos pesquisadores para divulgar sua produçáo científica revela que a maioria pertence à $\mathrm{CI}$, embora eles recorram a outros títulos de áreas correlatas, interdisciplinares, além de outros de áreas ainda mais distantes. A presença de tais artigos pode indicar aplicaçóes de metodologias ou teorias da CI à literatura de outra área, como pode ser o caso da revista Acta Cirúrgica Brasileira. 
Tabela 6 - Periódicos com maior número de publicaçóes pelos pesquisadores depois de seu ingresso nos grupos de pesquisa

\begin{tabular}{|l|l|l|}
\hline TÍTULO DO PERIÓDICO & $\mathrm{N}$ & $\%$ \\
\hline DataGramaZero & 71 & 14,9 \\
\hline Transinformação & 71 & 14,9 \\
\hline Ciência da Informação & 61 & 12,8 \\
\hline Perspectivas em Ciência da Informação & 51 & 10,7 \\
\hline Informaçáo e Sociedade: Estudos & 48 & 10,0 \\
\hline Encontros Bibli & 31 & 6,5 \\
\hline Scire: Representación y Organización del Conocimiento & 25 & 5,2 \\
\hline Ciencia de La Información & 19 & 4,0 \\
\hline Revista Brasileira de Biblioteconomia e Documentação & 18 & 3,8 \\
\hline Biblionline & 13 & 2,7 \\
\hline Informaçáo e Informaçáo & 12 & 2,5 \\
\hline Palavra-Chave & 7 & 1,5 \\
\hline Acta Cirúrgica Brasileira & 6 & 1,3 \\
\hline CENDOTEC & 6 & 1,3 \\
\hline Eptic On-Line & 6 & 1,3 \\
\hline São Paulo em Perspectiva & 6 & 1,3 \\
\hline Revista Comunicaçốes e Artes & 5 & 1,0 \\
\hline Ensaios APB & 5 & 1,0 \\
\hline Sciences de la Societé & 5 & 1,0 \\
\hline Comunicaçáo e Educação & 4 & 0,8 \\
\hline Education for Information & 4 & 0,8 \\
\hline TOTAL & 478 & 100 \\
\hline & & \\
\hline
\end{tabular}

Não se estranha, também, o fato de existir a possibilidade de artigo em interação com outra área. As revistas que mais publicaram no período estudado foram DataGramaZero e Transinformação, ambas com 71 artigos. Em segundo lugar, destacam-se a Ciência da Informação, com 61 artigos e Perspectivas em Ciência da Informação, 51 artigos. A DataGramaZero, a despeito de ser uma revista mais recente que as outras três que também publicam muito, oferece a vantagem de, desde sua criação, editar na forma digital. Além disso, tem periodicidade bimestral e publica, numericamente, maior número de artigos que as demais revistas. Esse formato, que passou a ser usado pelas demais revistas, traz agilidade não só na submissão de artigos, como, também, nas atividades ad hoc e na edição do fascículo. Essa agilidade é muito favorável ao pesquisador, que sempre precisa publicar com rapidez.

\section{Consideraçôes finais}

Apesar dos obstáculos, muitos deles descritos aqui, obtiveram-se resultados que mostram empenho da Ciência da Informação na formaçáo de grupos de pesquisa e o seu desenvolvimento e crescimento em números, bem como certo amadurecimento da comunidade científica da área, traduzida por meio da literatura disseminada. 
Contudo, alguns problemas necessitam de reflexôes mais aprofundadas e mais amplas, o que demandará, numericamente e qualitativamente, maior número de pesquisas.

Outra questão refere-se às políticas internas da área. As instituiçôes que representam docentes e pesquisadores poderiam consultar seus associados para a elaboração de uma agenda de pesquisa que priorize problemas considerados pela comunidade como prioritários e relevantes.

Alguns pesquisadores lideram mais de uma linha de pesquisa na mesma instituição, em temáticas diferentes. Esse comportamento, segundo consultores da CAPES, conforme consta dos relatórios trienais dos programas de pós-graduação, pode prejudicar as atividades dos programas e dificultar o desempenho do pesquisador que, se dedicado a uma só temática, poderá publicar maior número de documentos sobre a mesma, e com maior densidade. Pela literatura publicada e pela identificação da preferência temática do pesquisador, quando o mesmo permanece na pesquisa da mesma questáo, por longo tempo, sua produção é mais consistente. Verificou-se que aqueles grupos que investigam a mesma temática durante anos foram os mais produtivos, conduziram experimentaçóes e comprovaram metodologias e teorias e, assim, geraram novos conhecimentos. O Grupo de Produção Científica que se transformou em Núcleo de Pesquisa de Produção Científica é um exemplo dessa persistência na busca de construção de conhecimentos.

O intercâmbio entre pesquisadores parece estar crescendo, mas poderia ser maior com a participação de especialistas de diferentes instituiçôes em grupos empenhados na solução de problemas de uma mesma questão. Por outro lado, constatou-se que pesquisadores de um mesmo assunto em instituiçóes diferentes não desenvolvem estudos em colaboração.

Para que os Grupos de Pesquisa da Ciência da Informação melhorem seu desempenho será necessário que se dediquem somente aos problemas de uma temática, sem perder de vista a visão abrangente e desejada da área com um todo. No caso daqueles abrigados nos programas de pós-graduação, as orientações de doutores, mestres e de iniciação à pesquisa deveriam seguir a mesma temática da linha de pesquisa do orientador, o que evitaria a fragmentação. Desse modo, orientaçóes e atividades dos orientandos tornam-se mais colaborativas e a construção de conhecimento mais socializado.

Como última reflexão, é preciso esclarecer que a pesquisa científica em CIB se desenvolveu nas duas últimas décadas e a criação da Associação Nacional de Pesquisa e Pós-Graduação em Ciência da Informação (ANCIB) é um testemunho desse empenho dos pesquisadores da área. No entanto, seu reconhecimento e sua legitimidade dentre as outras comunidades e pela sociedade depende de maior visibilidade. Para isso seria necessário:

1. Concentrar esforços nos problemas básicos da CI, evitando a dispersão de temas.

2. Organizar e estruturar a pesquisa em torno das linhas de pesquisas da pósgraduação.

3. Criar grupos de pesquisa em consonância com a linha de pesquisa que o pesquisador orienta na pós-graduação.

4. Promover seminários e encontros temáticos entre pesquisadores, visando maior socialização dos mesmos. 
5. Refletir e desenvolver maior número de pesquisas sobre a interdisciplinaridade.

Espera-se que as análises realizadas nesta pesquisa contribuam para que as associaçôes da Ciência da Informação, as agências de fomento, as universidades e os institutos de pesquisa possam traçar metas e políticas para seus pesquisadores e estudantes de pós-graduação.

\section{Refêrencias bibliográficas}

CARNEIRO JR., S.; LOURENÇO, R. Pós-graduação e pesquisa na universidade. In: VIOTTI, E. B; MACEDO, M. M. Indicadores de ciência, tecnologia e inovação no Brasil. Campinas: UNICAMP, 2003. p. 41-88.

CASTRO, J. V. R. Análise da produçáo científica dos pesquisadores em Ciência da Informaçáo nos periódicos da área. 2009. 129 f. Dissertação (Mestrado em Ciência da Informaçáo) - Programa de Pós-Graduação em Ciência da Informação, Universidade Federal de Minas Gerais, Belo Horizonte. 2009.

CONSELHO NACIONAL DE DESENVOLVIMENTO CIENTÍFICO E TECNOLÓGICO (CNPq). Avaliaçáo e perspectiva 82. Brasília, 1983. v. 8: ciências sociais.

GOMES, Maria Y. F. S. de Filgueiras. A produção científica em Biblioteconomia e Ciência da Informação no Brasil: tendências temáticas e metodológicas. In: ENCONTRO NACIONAL DE PESQUISA EM CIÊNCIA DA INFORMAÇÃO (ENANCIB), 5., 2003, Belo Horizonte. Anais... Belo Horizonte: Associação Nacional de Pesquisa e Pós-Graduação em Ciência da Informação, 2003. 1 CD-ROM.

. Tendências atuais da produção científica em Biblioteconomia e Ciência da Informação no Brasil. DataGramaZero: Revista de Ciência da Informaçáo, v. 7, n. 3, 2006.

JARVELIN, K; VAKKARI, P. Content analysis of research articles in library and information science. Library \& Information Science, [S. 1.], n. 12, p. 395-421, 1990.

The evolution of library and information science 1965-1985: a content analisysis of journal articles. Information Processing \& Management, [S. 1.], v. 29, n. 1, p. 129$144,1993$.

McCLURE, C.; BISHOP, A. The status of research in Library / Information Science: guarded optimism. College \& Research Libraries, [S. 1.], p. 127-143, Mar. 1989.

OLIVEIRA, M. A investigaçáo científica na Ciência da Informaçáo: análise da pesquisa financiada pelo CNPq. 1998. 201 f. Tese (Doutorado em Ciência da Informação) - Programa de Pós-Graduação em Ciência da Informação, Universidade de Brasília, Brasília - DF. 1998.

PINHEIRO, L. V. R. A Ciência da Informaçáo entre sombra e luz: domínio epistemológico e campo interdisciplinar. 1997. 269 f. Tese (Doutorado em Ciência da Informação) - Programa de Pós-Graduação da Escola de Comunicações, Universidade Federal do Rio de Janeiro / Instituto Brasileiro de Informação em Ciência e Tecnologia, Rio de Janeiro. 1997.

POBLACION, D. A. A. Rumos da comunidade brasileira de pesquisadores em Ciência da Informação: desafios do século XXI. In: ENCONTRO NACIONAL DE PESQUISA EM CIÊNCIA DA INFORMAÇÃO (ENANCIB), 5., 2003, Belo Horizonte. Anais... Belo Horizonte: Associação Nacional de Pesquisa e Pós-Graduação em Ciência da Informação, 2003. 1 CD-ROM. 
SARACEVIC, T. Ciência da Informação: origem, evolução e relaçôes. Perspectivas em Ciência da Informaçáo, Belo Horizonte, v. 1, n. 1, p. 41-62, jan. / jun. 1996.

Information Science. Journal of the American Society for Information Science, [S. 1.], v. 50, n. 12, p.1051-1063, 1999.

UNIVERSIDADE ESTADUAL DE LONDRINA (UEL). Pró-Reitoria de Pesquisa e PósGraduação. Conceito de grupo de pesquisa. Disponível em: <www.uel.br/propp $>$. Acesso em: 28 ago. 2008.

UNIVERSIDADE ESTADUAL PAULISTA JÚLIO DE MESQUITA FILHO (UNESP). PróReitoria de Pesquisa. Definiçáo de grupo de pesquisa. 2007. Disponível em: <http://www. rc.unesp.br/comissoes/comissóes/Pibic07_08/gruposdepesquisa>. Acesso em: 16 maio 2009. 